\title{
HISTORY AND APPLICATIONS OF SPACE-BORNE LIDARS
}

\author{
Fatemeh Fouladinejad ${ }^{1}$, Aliakbar Matkan ${ }^{1}$, Mohammad Hajeb ${ }^{1}$, Foad Brakhasi ${ }^{1}$ \\ ${ }^{1}$ Remote sensing and GIS Center, University of Shahid Beheshti, Tehran, Iran
}

KEYWORDS: LIDAR, Space-borne, Vertical Structure, ICESat, CALIPSO, CATS, ADM-Aeolus

\begin{abstract}
ABSTRCT:
LIDAR (Light Detection and Ranging) is a laser altimeter system that determines the distance by measuring pulse travel time. The data from the LIDAR systems provide unique information on the vertical structure of land covers. Compared to ground-based and airborne LIDARs providing a high-resolution digital surface model, space-borne LIDARs can provide important information about the vertical profile of the atmosphere in a global scale. The overall objective of these satellites is to study the elevation changes and the vertical distribution of clouds and aerosols. In this paper an overview on the space-borne laser scanner satellites are accomplished and their applications are introduced. The first space-borne LIDAR is the ICESat (Ice, Cloud and land Elevation Satellite) satellite carrying the GLAS instrument which was launched in January 2003. The CALIPSO (the Cloud-Aerosol Lidar and Infrared Pathfinder Satellite Observations, 2006), CATS-ISS (the Cloud-Aerosol Transport System, 2015), ADM-Aeolus (Atmospheric Dynamics Mission, 2018), and ICESat-2 (Ice, Cloud and land Elevation Satellite-2, 2018) satellites were respectively lunched and began to receive information about the vertical structure of the atmosphere and land cover. In addition, two ACE (The Aerosol-CloudEcosystems, 2022) and EarthCARE (Earth Clouds, Aerosols and Radiation Explorer, 2021) space-borne satellites were planned for future. The data of the satellites are increasingly utilized to improve the numerical weather predictions (NWP) and climate modeling.
\end{abstract}

\section{INTRODUCTION}

LIDAR is a laser altimeter that obtains the distance between the sensor and desired objects by measuring pulse travel time. The data from LIDAR systems potentially provide high accuracy 3D information from a surface of interest (Ranson et al., 2004). In the other word, LIDAR data can present estimations of stand volume such as biomass and man-made structures. Compared to radar, LIDAR use shorter wavelengths to gain more detail. However, the light cannot penetrate optically thick layers such as clouds.(http://www.eohandbook.com/eohb2011/earth_lidars.ht $\mathrm{ml})$.

LIDAR systems are divided into three major categories: groundbased, airborne, and space-borne. The first LIDARs were ground-based systems. Terrestrial laser scanners are one of these systems mostly applied for indoor environment mapping. There is also a more recently uplooking type of ground based LIDARs (e.g. AERONET and MLPNET) which have been employed for atmospheric studies. After successfully implementation of ground based systems in the 1960s, laser scanners were mounted on aerial platforms. Airborne laser scanners (ALS) with downlooking configurations can acquire 3-D point cloud mainly used to prepare digital surface models (DSM). This system has some problems such as the inherent costs for aircraft operation, flight restrictions, and data acquisition at a local scale (McCormick, 2005). The Needs to study of vertical structure of the atmosphere at high temporal resolution and the global scale led to the emergence of space-borne LIDARs. Today, satellite LIDARs have provided new capabilities for measuring the Earth's atmosphere from space (Winker et al., 2006).
In this overview, we try to introduce the LIDAR satellites and their unique features and applications, and argue challenges and limitations of them.

\section{SPACE-BORNE LIDAR BASED SATELLITES}

Over the past several decades, various types of LIDARs have been developed. In the meantime, it is worth mentioning that LIDAR has been very capable in remote sensing due to simultaneous measurements at different wavelengths and polarization modes (Oppel, 2000). Space-borne LIDAR satellites provide unique information of various parameters in the atmosphere at the global scale. We will divide the space-borne LIDAR satellites into three categories: complete mission (ICESat, CATS-ISS), current mission (CALIPSO, ADMAeolus, ICESat-2), and future mission (EarthCARE and ACE). The Timelines of historical, current and planned LIDAR satellite along with their characteristics is shown in Fig. 1.

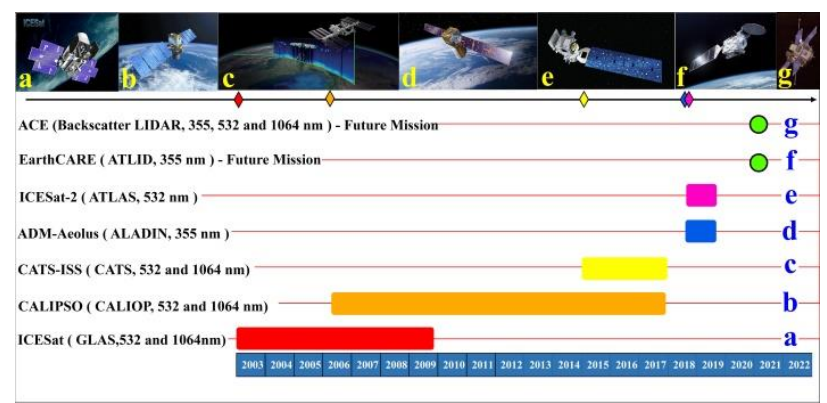

Fig. 1. Timelines of the space-borne LIDARs.

\subsection{ICESat satellite}


ICESat satellite (Fig1.a), as a part of NASA's Earth Observation System (EOS), was launched in 2003 by delta II vehicle (altitude $600 \mathrm{~km}$, orbit inclination 94, Repeat cycle 183 days). It has two GLAS (Geoscience Laser Altimeter System) and GPSP (Global Positioning System Payload) sensors (https://eospso.gsfc.nasa.gov/missions/ice-cloud-and-landelevation-satellite). A precision "Blackjack" GPS receiver will indicate GLAS's location in orbit (https://www.nasa.gov/pdf/162309main_ICESat_Brochure.pdf). The GLAS was a laser scanner altimeter system which collects data vertically at 532 and $1064 \mathrm{~nm}$, between $86^{\circ} \mathrm{N}$ and $86^{\circ} \mathrm{S}$ latitude. A $1064 \mathrm{~nm}$ detector is used to measure surface elevation and dense cloud height. It is also used to measure the shape of the echo pulse and height from thicker clouds. Also, the $532 \mathrm{~nm}$ channel is used to measure the height of the atmospheric boundary layer and the vertical distribution of aerosol and thinner clouds. The satellite has more than $60 \mathrm{~m}$ diameter laser footprints with a distance of 172 meters along-track. (https://www.science.gov/topicpages/i/icesat+laser+altimeter; https://www.nasa.gov/pdf/162309main_ICESat_Brochure.pdf). The instrument used pulsed lasers and a direct detection receiver consisting of a waveform digitizer and a silicon avalanche photodiode (Sun et al., 2017).

For the first time, The GLAS instrument is capable to provide accurate multi-year height profiling of atmospheric cloud and aerosol layers directly from space (https://www.nasa.gov/pdf/162309main_ICESat_Brochure.pdf). ICESat mission was to measure the height of aerosols and clouds, especially stratospheric clouds, as well as information on topography and vegetation around the world (https://www.nasa.gov/mission_pages/icesat). This satellite is also able to acquire information about the vertical and horizontal distribution of tropical clouds as well (Dessler et al., 2006). Moreover, it detects top of the clouds at the point in which optical depth exceeds 0.002-0.02 measured from the top of the cloud downward (Dessler et al., 2006). However, the main objective of the satellite is to obtain data in order to cryosphere monitoring including data related to the balance of the masses of ice sheets (https://icesat-2.gsfc.nasa.gov/science) and sea ice thickness distribution. Another major objective of the satellite was to determine long-term and inter-annual variations in ice sheets with a precision of more than $2 \mathrm{~cm}$. (Schutz et al., 2005).

ICESat provided significant estimates of the ice sheet mass balance and identify areas with rapid ice sheet elevation changes, especially in sloping margins. Furthermore, ICESat obtained high-accuracy elevation data in a consistent, Earth-centered reference frame, That, it is suitable for establishing global geodetic control (Zwally et al., 2002).

Various products of the GLAS instrument were used in different applications including cloud-top heights (Dessler et al., 2006), forest stand characteristics (Ranson et al., 2004), forest canopy height (Wang et al., 2014), estimating Siberian timber volume (Nelson et al., 2009), elevation changes of Tibetan lakes (Abshire et al., 2005), and water level changes of high altitude lakes in Himalaya-Karakoram (Srivastava et al., 2013), detection Polar "diamond dust" (https://www.nasa.gov/pdf/162309main_ICESat_Brochure.pdf). This satellite provides elevation data that offer the potential to monitor small water areas due to its small footprints (50 to
$90 \mathrm{~m}$ ) (Baghdadi et al., 2011). Table 1 gives the various products of GLAS instrument and their corresponding product level.

Table 1. The products of GLAS instrument

(https://nsidc.org/data/icesat/data.html)

\begin{tabular}{cl}
$\begin{array}{c}\text { Product } \\
\text { level }\end{array}$ & \multicolumn{1}{c}{ Product } \\
\hline L0 & GLAS instrument packet (GLAH00) \\
\hline L1A & $\begin{array}{l}\text { Altimetry Data (GLAH01), Atmosphere Data (GLAH02), } \\
\text { Engineering Data (GLAH03), Laser Pointing Data } \\
\text { (GLAH04) }\end{array}$ \\
\hline L1B & $\begin{array}{l}\text { Waveform-based Elevation corrections (GLAH05), } \\
\text { Elevation (GLAH06), Backscatter(GLAH07) }\end{array}$ \\
\hline L2 & $\begin{array}{l}\text { Boundary Layer Height (GLAH08), Cloud Height for } \\
\text { Multiple Layers (GLAH09), Aerosol Vertical } \\
\text { Structure(GLAH10), Thin Cloud/Aerosol Optical Depth } \\
\text { (GLAH11), Ice sheet Elevation (GLAH12), Sea ice } \\
\text { Roughness (GLAH13), Land/Canopy Elevation } \\
\text { (GLAH14), Ocean Elevation (GLAH15) }\end{array}$ \\
\hline L3 & Time, Surface characteristics, Atmospheric parameters \\
\hline
\end{tabular}

The GLAS obtain global land elevation data in two products GLA06 and GLA14. The GLA06 data included surface elevations of smooth and non-vegetated terrain (Urban et al.2008). The GLA14 is usually used for rough terrain surfaces (Nuth and K"äab, 2011). The GLAS cannot be used for routine monitoring because some tracks are possible with ICESat because of meteorological conditions and power safety (Baghdadi et al., 2011). This instrument was as a scientific and technical pathfinder for future orbiting LIDAR missions (Sun et al., 2017).

One of the challenges on the ICESat satellite was the problem of measuring the height change for the outlet glaciers, because ICESat carried a single-beam laser altimeter instead of multi beam one. Also, a single beam laser of GLAS instrument was not able to separate slope effects from elevations changes on an orbit-by-orbit basis and so many years of data were needed to separate these two effects (Markus et al., 2017). This problem was resolved by the ICESat-2 satellite. Additionally, GLAS does not show a perfect view of the diurnal cycle of the occurrence of the cloud (Dessler et al., 2006). Off nadir pointing the ICESat space-borne results in averagely 12-day profiling features that have to be targeted on near the equator, and even more frequently at higher latitudes.

The ICESat mission ended in 2009. Following the restrictions of ICESat, the ICESat-2 satellite was scheduled for 2018. But before the launch of the ICESat-2 satellite, two CALIPSO and CATS satellite has been launched to the space.

\subsection{CALIPSO satellite}

The CALIPSO Satellite (Fig1.b), a joint product of U.S. (NASA) and French (Centre National d'Etudes Spatiales/CNES), was launched in 2006 by vehicle Delta II. Its altitude is $705 \mathrm{~km}$, orbit inclination is $98.2^{\circ}$ with a sun-synchronous orbit type and repeat cycle is 16 days. The satellite provides atmospheric measurements that are near Simultaneous with observations from AIRS, MODIS and CERES instrument on Aqua (Winker et al., 2007).

It has three sensors:

CALIOP (Cloud-Aerosol Lidar with Orthogonal Polarization), IIR (Imaging Infrared Imager), and WFC (Wide-Field Camera). 
CALIOP instrument measures between latitudes of $82 \circ \mathrm{S}$ and $82 \circ \mathrm{N}$. the instrument is first LIDAR optimized for aerosol and cloud measurement from space (Costantino and Bréon, 2010). CALIOP has three channels, which includes one 1064-nm channel and two 532-nm channels that are orthogonal (parallel and perpendicular polarization) (Poole et al., 2003), With Resolution: vertical sampling: $30 \mathrm{~m}, \quad 0-40 \mathrm{~km}$. Laser Divergence/Footprint $100 \mu \mathrm{rad} / \approx 70 \mathrm{~m}$ and Telescope Divergence/Footprint is $130 \mu \mathrm{rad} / \approx 90 \mathrm{~m}$.

IIR instrument provides calibrated radiances at 8.7, 10.6, and 12 $\mu \mathrm{m}$ with $64 \mathrm{~km}$ swath. It can be said these wavelengths are to optimize joint IIR/LIDAR retrievals of particle size and cirrus emissivity.

WFC instruments has a single channel at $645 \mathrm{~nm}$ that obtain images of a $61 \mathrm{~km}$ swath that its spatial resolution is $125 \mathrm{~m}$. In addition, this sensor provides meteorological context for the LIDAR measurements, and also, enables accurate spatial registration between CALIPSO and other instruments in other Aqua constellation (Winker et al., 2003).

These instrument work independently and continuously. However, WFC instrument obtains scientific data only in daylight (Winker et al., 2003). WFC and IIR data are capable to retrieve cloud features (Winker et al., 2003).

CALIOP profiles provide information such as the vertical distribution of aerosols and clouds and the classification of aerosols' sub-types (Winker et al., 2006).

The vertical and horizontal resolutions for CALIOP data (Fig.2) varies with altitudes (https://www.calipso.larc.nasa.gov/resources/calipso_users_gui de/essential_reading/index.php).
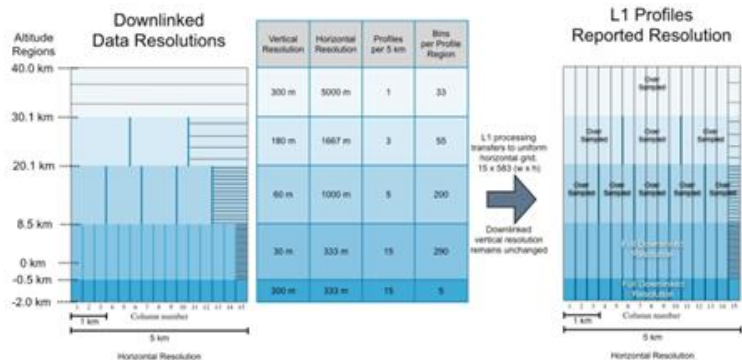

Fig. 2. The vertical and horizontal resolutions of CALIOP data.

As can be seen from Fig.2, the highest resolution is belonging to lower troposphere where the spatial variability of clouds and aerosols is the greatest. Since the CALIPSO mission was to better understand the role of aerosols and clouds in the climate system (Winker et al., 2006), this satellite along with the Cloudsat satellite, was placed in a polar orbit at an altitude of 705 $\mathrm{km}$ above the ground as a part of "A-Train Constellation," socalled "Afternoon Train Constellation" (Poole et al., 2003).

Due to the short time scales as well as nonlinear relationships of cloud processes, almost concurrent observations of atmospheric state, aerosol and cloud optical properties, also, radiative fluxes are need to experiment the ability of cloud models to reproduce the physics of cloud-radiation feedbacks. CALIPSO with four other satellites in the constellation Aqua, Together, have been able to provide a comprehensive set of measurements of atmospheric state and the optical features of clouds and aerosols as well as radiation fluxes. Syntactic these lead to fundamental advances in our understanding of the relation between clouds, aerosols, also, radiation for accurately evaluation future climate change (Winker et al., 2003).
The ability of profiling of CALIOP can help to distinguish clouds embedded in layers from those lied above or below aerosols (Winker et al., 2003).

Model estimates of the radiative forcing by aerosol are unclear, due to the insufficient current ability to view aerosols from space. The CALIPSO, by providing global and vertical measurements of aerosols distribution, enhances current capabilities and provides the ability to discrimination aerosols into several types as well as the ability to view aerosols over heterogeneous and bright surfaces (Winker et al., 2003).

These data of CALIOP provide the opportunity to describe the global 3D distribution of aerosol also seasonal and inter-annual variations. With that goal in mind, a monthly global dataset of daytime and nighttime aerosol extinction profile is available and known as Level3 aerosol product (Winker et al., 2013).

Various research fields such as monitoring of stratospheric aerosol and aerosol distribution (Thomason et al., 2007), estimating the ocean subsurface (Lu et al., 2014), documenting shallow subsurface oil (Leifer et al., 2012), global distributing of the clear-sky occurrence rate during the daytime (Eguchi and Yokota, 2008), and dust detection (Luo et al., 2015; Brakhasi et al., 2018) have been studied using CALIPSO LIDAR observations. The various products of CALIOP and their corresponding product level are given in table 2 .

Table2. The products of CALIOP instrument (https://eosweb.larc.nasa.gov/project/calipso/calipso_table)

\begin{tabular}{|c|c|}
\hline $\begin{array}{l}\text { Product } \\
\text { Level }\end{array}$ & Product \\
\hline Level 1 & Calibrated and Geolocated Profiles \\
\hline $\begin{array}{c}\text { Level } \\
1.5\end{array}$ & $\begin{array}{l}\text { data product is a continuous segment of calibrated, } \\
\text { Geolocated, cloud-cleared, and spatially averaged profiles } \\
\text { of LIDAR attenuated backscatter (Spatial Resolution } \\
333 \mathrm{M} \text { and 20km)and aerosol extinction (Spatial } \\
\text { Resolution 333M) }\end{array}$ \\
\hline Level 2 & $\begin{array}{l}\text { Aerosol Profiles and Layers, Cloud Profiles and Layers, } \\
\text { Merged Aerosol and Cloud Layers, Vertical Feature } \\
\text { Mask, Polar Stratospheric Cloud, Blowing Snow } \\
\text { Antarctica Data }\end{array}$ \\
\hline Level 3 & $\begin{array}{l}\text { All-Sky Aerosol Extinction Profiles, Cloud-Free Aerosol } \\
\text { Extinction Profiles, Cloudy-Sky, Transparent Aerosol } \\
\text { Extinction Profiles, Cloudy-Sky, Opaque Aerosol } \\
\text { Extinction Profiles, Ice Cloud Extinction Coefficient and } \\
\text { Ice Water Content Histograms Product, Cloud } \\
\text { Occurrence, Stratospheric Aerosols Profiles }\end{array}$ \\
\hline
\end{tabular}

Despite the benefits of the CALIPSO, it has a diurnal gap. Considering spatial variability of aerosols and clouds, the information is just available on the overpasses and between the orbits there is no information at all. This problem was somehow solved by the CATS satellite by focusing on the $50^{\circ} \mathrm{S}$ to $50^{\circ} \mathrm{N}$ latitude where the most important atmospheric events e.g. sever dust storms are occurred. Despite CALIOP and CATS instruments orbits, lacking of information between the orbits are remain as a weakness.

\subsection{CATS-ISS satellite}

CATS onboard the international space station (ISS) (Fig1.c) were launched in 2015 by Spacex Falcon 9. Its altitude is 420 $\mathrm{km}$, orbit inclination is $51.65^{\circ}$ with a non-sun-synchronous orbit type and repeat cycle nearly 3 days. 
It continued with spectral resolution of $532 \mathrm{~nm}, 355 \mathrm{~nm}$ and 1064 $\mathrm{nm}$ and similar to CALIOP sensor with parallel and perpendicular polarization on the $1064 \mathrm{~nm}$, and can be considered as a bridge between the CALIPSO satellite and the Earth CARE satellite. CATS is designed for a variety of new capabilities such as prediction of aerosols and lowering the risk for next science missions (Platnick, 2013). CATS is the first LIDAR sensor to provide near-real-time information (less than six hours). It can also view identical locations at different times, and its unique ability to study daily changes in clouds and other parameters in the atmosphere (Platnick, 2017), the thing that overcomes the diurnal gap of CALIPSO.

Its data is used in different applications such as monitoring volcanic sulfur dioxide (SO2) (Hughes et al., 2016) and diurnal cycle of cloud profiles over land and ocean (Noel et al., 2018). After successful 33-month mission of operation onboard the ISS, CATS has ended on-orbit operations (https://directory.eoportal.org/web/eoportal/satellitemissions/i/iss-cats). Although CATS instrument focuses on the middle latitude from $50^{\circ} \mathrm{S}$ to $50^{\circ} \mathrm{N}$, the investigating polar thin clouds and aerosols using its data is not possible. The CATS data product levels are defined in table 3 .

Table 3. The CATS data products (Palm et al., 2018)

\begin{tabular}{cl}
$\begin{array}{l}\text { Product } \\
\text { level }\end{array}$ & \multicolumn{1}{c}{ Product } \\
\hline Level 0 & $\begin{array}{l}\text { Reconstructed, unprocessed instrument data at raw } \\
\text { resolutions (i.e., the downlinked raw photon counts from } \\
\text { the CATS instrument). Any and all communications } \\
\text { artifacts (e.g. synchronization of packets, communications } \\
\text { headers, duplicate or missing data) are removed in the L0 } \\
\text { process. }\end{array}$ \\
\hline Level & $\begin{array}{l}\text { Level 0 data that is time-referenced, geo-located, } \\
\text { 1A }\end{array}$ \\
& $\begin{array}{l}\text { artifacts, normalized to laser energy, and annotated with } \\
\text { ancillary information. The CATS Level 1A data (relative } \\
\text { normalized backscatter) is an internal product only and is } \\
\text { not distributed. }\end{array}$ \\
\hline Level & $\begin{array}{l}\text { Level 1A data that have been calibrated, annotated } \\
\text { with ancillary meteorological data, and processed to } \\
\text { 1B }\end{array}$ \\
sensor units. The CATS Level 1B data (attenuated total \\
backscatter and depolarization ratio) is archived as Level \\
1 data.
\end{tabular}

\subsection{ADM-Aeolus satellite}

Measurements of winds throughout the atmosphere are very important and crucial for numerical weather forecast and also for climate studies. However, there wasn't observations of height profiles in the global wind field. For this reason, the European Space Agency decided to create a Doppler wind LIDAR mission, that called Atmospheric Dynamics Mission ADM-Aeolus (Reitebuch., 2012).

Aeolus as a core mission of ESA (European Space Agency) was launched into space on 22 August 2018 to provide wind profile measurements. ADM-Aeolus (Fig1.d) is a project for the Global Climate Observing System (GCOS) carries the first wind LIDAR instrument in space namely ALADIN (Atmospheric Laser Doppler Instrument) which operates at $355 \mathrm{~nm}$. The UV spectrum result in increment in molecular Rayleigh backscatter, which is inversely proportional to the fourth power of the wavelength. This wavelength was selected for technical reasons, owing to it can be generated with a Nd:YAG laser through tripling its frequency with non-linear crystals and lower wavelengths in the UV spectral region are absorbed by stratospheric ozone (Reitebuch, $r \cdot 1 r$ ).

The optical receiver has two spectrometers: Mie and Rayleigh, Mie spectrometer measures aerosol and cloud particles backscatter and Rayleigh spectrometer measures the Doppler frequency shift from molecular backscatter (Reitebuch, 2012). ADM-Aeolus has a Sun-synchronous orbit at the altitude of 320 $\mathrm{km}$, inclination 97 degree with a 7-day repeat cycle (111 orbits). Considering resolutions, it has 1 and $3.5 \mathrm{~km}$ vertical and horizontal resolution respectively which covers altitudes from - 1 to $26.5 \mathrm{~km}$. Laser Divergence/Footprint $12 \mu \mathrm{rad} / \approx 6 \mathrm{~m}$ Telescope Divergence/Footprint $19 \mu \mathrm{rad} / \approx 9 \mathrm{~m}$

ALADIN employs the DWL (Doppler Wind Lidar) measurement technique and contains the Attitude and Orbit Control System (AOCS), power system contains lithium-ion batteries and gallium-arsenide solar arrays, also S-band and X-band antennas with frequencies and wavelengths $2.030 \mathrm{GHz}$ and $14.8 \mathrm{~cm}$ for Sband and $8.040 \mathrm{GHz}$ and $3.73 \mathrm{~cm}$ for X-band for data downlink and telemetry data link from the ground stations (Reitebuch, 2012).

The observation from ALADIN serves as an input to heighten the accuracy of Numerical Weather Prediction (NWP) models and climate prediction. The data (have not been yet released) will improve our understanding of atmospheric dynamics including the global transport of energy, water, aerosols, chemicals and processes relevant to climate variability. One of advantages of this satellite is that it located at lower altitude and its measurements will be delivered rapidly, improving weather forecasts.

ADM mission will obtain profiles of one component of horizontal wind vector from ground up to the lower stratosphere $(20-30 \mathrm{~km})$ that it is perpendicular to the flight track. (Reitebuch et al., 2009; Reitebuch, 2012).

The main product of the ADM mission is the Level 1B dataset. This includes calibrated wind velocity observations for the Rayleigh and Mie channels. Products of this level are delivered globally to a number of meteorological services centers and for selected regions, within 3 hours after sensing (NRT service) and within 30 minutes after sensing, Respectively (https://directory.eoportal.org/web/eoportal/satellite-

missions/a/aeolus). The data for this product are obtained only from ALADIN sensor and AOCS system. While, Level 2 products uses information from other sources, for example atmospheric temperature and pressure characteristics to correct the winds derived with the Rayleigh spectrometer from the pressure and temperature affiliate signal bandwidth of the Rayleigh-Brillouin scattering (Dabas et al.2008).

Information of clouds and aerosols optical properties at level 2A and horizontal line-of-sight wind observations at level 2B after temperature/pressure corrections and classification of the measurements within one view are available. The use of Level 2B data in the ECMWF Operational Prediction Model will provide Aeolus auxiliary wind data product (Level 2C). (https://directory.eoportal.org/web/eoportal/satellite- 
missions/a/aeolus). The contents represented in the satellite products are given in table 4.

Table 4. The ADM-Aeolus products

((https://earth.esa.int/web/eoportal/satellite-missions/a/adm-aeolus) Product Contents

Level 0 Raw 'science' source packets including unprocessed instrument and platform telemetry, packet quality parameters

Level 1B Engineering calibrated wind velocity data (preliminary one component wind observations), including viewing geometry, scene geolocation and ground echo data

Level 2A Supplementary data product for cloud and aerosol optical properties (layer backscatter and extinction coefficient, top /base heights, optical depth....), including viewing geometry, scene geolocation data and error quantifiers

Level 2B Consolidated geolocated wind observations after atmospheric corrections and scene classification, including additional geophysical parameters and error quantifiers

Level 2C Aeolus assisted wind data, result of NWP assimilation processing, including vertical wind vector profiles (u \& v components) and supplementary geophysical parameters

\subsection{ICESat-2 satellite}

ICESat-2 satellite (Fig1.e), was launched at 2018 by delta II vehicle. Its altitude is $481 \mathrm{~km}$, orbit inclination is $92^{\circ}$ with a nonsun-synchronous orbit type and repeat cycle is 91 days. The mission is one of NASA launcher missions by the U.S. National Research Council (NRC) (https://eospso.gsfc.nasa.gov/missions/ice-cloud-and-landelevation-satellite-2). This satellite as a highest-resolution laser altimeter provides better spatial resolution $(0.15 \mathrm{~m})$ and smaller footprint than ICESat, a multi-beam system and ability to resolve rougher terrains (Markus et al., 2017). It also examines cloud type, landscape topography, cloud type and its temperature, the height of forests, lakes and urban areas, getting information of waterways, wetlands, reservoirs, tundra, and agricultural fields (https://icesat-2.gsfc.nasa.gov/science).

While ICESat-2's laser beams can penetrate through some wispy clouds, other clouds will block the beam, and the light reflects back to the satellite. (https://icesat2.gsfc.nasa.gov/science). This satellite carries ATLAS (Advanced Topographic Laser Altimeter System) and GPSP (Global Positioning System Payload) sensors. ATLAS, a LIDAR system, is a photon-sensitive surface. This technology has many advantages in spatial altimetry (Neuenschwander And Magruder, 2016). ATLAS instrument has two laser operating at $532 \mathrm{~nm}$ with transmitter optics for beam steering and a diffractive optical element that divides the signal into 6 separate beams as well as a wavelength tracking system and receivers for start pulse detection. This also, applied with multi-beam micro-pulse photon-counting LIDAR altimetry and its purpose is measuring ice-surface heights at $0.7-\mathrm{m}$ along-track spacing and the sensor is sketched to resolve temporal and spatial diversity of rapidly changing glaciers and ice sheets (https://www.science.gov/topicpages/i/icesat+laser+altimeter\#). The differences in the ICESat- 2 measurement concept are a result of overcoming some limitations associated with the approach used in the ICESat mission. The beam pair configuration of ICESat- 2 allows for the determination of local cross-track slope, a significant factor in measuring elevation change for the outlet glaciers surrounding the Greenland and Antarctica coasts. The multiple beam pairs also provide improved spatial coverage.
The aims of the ICESat-2 mission include to continue estimation of ice sheet elevation and sea ice freeboard to determine their changes (Markus et al., 2017). Besides, the detection of ground under dense canopy (Herzfeld et al., 2014), generating wall-towall AGB maps (Narine et al., 2019), estimating vegetation cover and biomass in a dry land ecosystem (Glenn et al., 2016) have been done based on the simulated data. It should be mentioned that the real data of the satellite have not been yet released. Comparing with ICESat, the beam pair configuration of ICESat-2 allows for the determination of local cross-track slope. In ICESat-2, spatial resolution was also improved and it has a smaller footprint and a multi-beam instrument. It also capable of measuring cross slopes (Markus et al 2017).

ICESat-2 is able to get more details of the altitudes and in addition it can fill in the gaps in coverage. In clear waters the satellite is able to record the seafloor up to $30 \mathrm{~m}$ below the surface. In forests case studies, the satellite detects both the upper layer of the canopy and the forest floor, allowing calculation of the vegetation mass (https://directory.eoportal.org/web/eoportal/satellitemissions/i/i cesat-2). A noteworthy attribute of ATLAS is that engineers enabled the satellite to control how it is positioned in the space, which is relevant because ATLAS records the distance from itself to the ground, and the measurement recorded for Earth's elevation will be off as well. Also, engineers constructed the laser reference system confirming that the laser is adjusted in agreement to the telescope. If either the laser or the telescope is off, the satellite can make its own adjustments hence (https://icesat-2.gsfc.nasa.gov/how-it-works). Table 5 represents the product level of ICESat-2.

Table 5. The products level of ICESat-2 (https://nsidc.org/data/icesat-2)

\begin{tabular}{|c|c|}
\hline $\begin{array}{l}\text { Product } \\
\text { level }\end{array}$ & Product \\
\hline L1 & $\begin{array}{l}\text { Reformatted Telemetry (ATL01), Science Unit Converted } \\
\text { Telemetry (ATL02) }\end{array}$ \\
\hline L2 & $\begin{array}{l}\text { Global Geolocated Photon Data (ATL03), Normalized } \\
\text { Relative Backscatter (ATL04) }\end{array}$ \\
\hline L_3A & $\begin{array}{l}\text { Land Ice height (ATL06), Sea Ice Height (ATL07), Land } \\
\text { and Vegetation Height (ATL08), Atmospheric Layer } \\
\text { Characteristics (ATL09), Sea Ice Freeboard (ATL10), } \\
\text { Ocean Surface Height (ATL12), Inland Water Surface } \\
\text { Height (ATL13) }\end{array}$ \\
\hline L_3B & $\begin{array}{l}\text { Annual Land Ice Height (ATL11), Gridded Annual Ice } \\
\text { Sheet Height (ATL14), Ice Sheet Height Change } \\
\text { (ATL15), Gridded Weekly (ATL16), Monthly (ATL17) } \\
\text { Atmosphere, Gridded Land and Vegetation Height } \\
\text { (ATL18), Gridded Monthly Sea Surface Height: Open } \\
\text { Ocean (ATL19), Gridded Monthly Sea Ice Freeboard } \\
\text { (ATL20), Sea Surface Height: Ice-Covered Ocean } \\
\text { (ATL21) }\end{array}$ \\
\hline
\end{tabular}

\subsection{EarthCARE satellite}

The newest ESA's LIDAR satellite launch program is related to the EarthCARE (Fig1.g) mission and has been scheduled for 2021 with altitude $393 \mathrm{~km}$, orbit inclination 97\% Repeat cycle 25 days and orbit type sun-synchronous. EarthCARE will carry four instrument.

Atmospheric LIDAR (ATLID): High-spectral-resolution. 355 $\mathrm{nm}$ linearly polarized laser. Rayleigh and Mie co-polar and total cross-polar channels. Vertical-resolution $103 \mathrm{~m}$ from -1 to $20 \mathrm{~km}$ in height and $500 \mathrm{~m}$ from 20 to $40 \mathrm{~km}$. Horizontal resolution 285 $\mathrm{m}$ (two shots). Telescope diameter $0.62 \mathrm{~m}$. Beam divergence 45 
$\mu \mathrm{rad}$, ground footprint about $30 \mathrm{~m}$. Receiver field of view $65 \mathrm{rad}$ Pointing $3^{\circ}$ off-nadir along track to avoid specular reflection from ice crystals.

Broadband Radiometer (BBR): 3 views: forward, nadir, backward with thenith angle $50^{\circ}$; Channels: $0.25-4.0 \mu \mathrm{m}$ and $0.25-50 \mu \mathrm{m}$; Linear microbolometer array detectors, ground pixels $<1 \mathrm{~km} \times 1 \mathrm{~km}$.

Cloud Profiling Radar (CPR): $3.3 \mu$ s pulses; pulse repetition frequency $6100-7500 \mathrm{~Hz}$; Beam footprint on ground < $800 \mathrm{~m}$; oversampling $100 \mathrm{~m}$ down to $1 \mathrm{~km}$ below the surface; $500-\mathrm{m}$ vertical resolution and horizontal sampling $500 \mathrm{~m}$; Antenna subtended aperture $2.5 \mathrm{~m}$; Nadir pointing. $0.095^{\circ}$ beam width; Doppler capability.

Multispectral Imager (MSI): cross-track observations (150 km swath); Nadir push-broom imager; seven channels: 0.670, 0.865, 1.65, 2.21, 8.80, $10.80, \quad$ and $12.00 \mu \mathrm{m}$ (https://www.mpimet.mpg.de/fileadmin/staff/luebkeanna/earthc are_factsheet_draft4.pdf; Illingworth et al., 2015 and Eisinger et al., 2012) Sampling (eff.): horizontal $500 \mathrm{~m} \times 500 \mathrm{~m}$.

EarthCARE satellite with wavelength $355-\mathrm{nm}$ with highspectral-resolution LIDAR enable to measure directly and accurately cloud and aerosol extinction and optical depth. compounding this with backscatter and polarization information to cause good ability to identify aerosol type (Illingworth et al., 2015). EarthCARE will provide information to distinguish different aerosol types (Hayer et al., 2018), vertical distributions of atmospheric liquid water, ice, cloud distribution, the characteristics of vertical motions within clouds also cloudprecipitation interactions (https://www.mpimet.mpg.de/fileadmin/staff/luebkeanna/earthc are_factsheet_draft4.pdf). And retrieve profiles of atmospheric radiative heating also cooling at the global scale.

EarthCARE Products level are shown in table 6.

\begin{tabular}{|c|c|}
\hline & $\begin{array}{l}\text { Table 6. EarthCARE Products } \\
\text { (Eisinger et al., 2017) }\end{array}$ \\
\hline Product level & Product \\
\hline L_0 & annotated raw instrument science packets \\
\hline L_1B & $\begin{array}{l}\text { fully calibrated and geolocated instrument science } \\
\text { measurements on the native instrument grid. } \\
\text { For ATLID instrument: Attenuated backscatter } \\
\text { profiles }\end{array}$ \\
\hline $\begin{array}{c}\mathrm{L} \_1 \mathrm{C} \text { (MSI } \\
\text { only) }\end{array}$ & $\begin{array}{l}\text { MSI level } 1 \mathrm{~b} \text { data interpolated to a spatial grid } \\
\text { common to all MSI bands. The grid spacing is } \\
\text { similar to the one of MSI level } 1 \mathrm{~b} \text {. }\end{array}$ \\
\hline L_1D & $\begin{array}{l}\text { spatial grid shared by all instruments ("joint } \\
\text { standard grid") and ECMWF meteorological fields } \\
\text { limited to EarthCARE swath }\end{array}$ \\
\hline L_2A & $\begin{array}{l}\text { Single-instrument geophysical products. For } \\
\text { ATLID instrument is: feature mask and target } \\
\text { classification, extinction, backscatter and } \\
\text { depolarization profiles, aerosol properties, ice cloud } \\
\text { properties }\end{array}$ \\
\hline L_2B & $\begin{array}{l}\text { Synergistic geophysical products (using data from } \\
\text { two or more instruments), Aerosol and cloud } \\
\text { products that synergistic of ATLID and/or CPR } \\
\text { and/or MSI data. }\end{array}$ \\
\hline
\end{tabular}

\subsection{ACE satellite}

ACE (Fig1.f) is scheduled for 2022 with altitude $650 \mathrm{KM}$, orbit inclination $98.2^{\circ}$ and orbit type sun-synchronous. The satellite includes five sensors called the LIDAR, Cloud Radar, Multiband VV/VIS spectrometer, Next Gen APS and OCI. (http://database.eohandbook.com/database/missionsummary.asp $\mathrm{x}$ ?missionID=648)

OCI instrument: (sampling: imaging, resolution $1 \mathrm{~km}$, swath $2500 \mathrm{~km}$, waveband UV-NIR (350 - $800 \mathrm{~nm})$; SWIR (940, 1240, $1378,1615,2130$ and $2260 \mathrm{~nm})$ ) is multi-purpose imagery (ocean), And measure Ocean imagery and water leaving radiance.

Multi-band VV/VIS spectrometer instrument: ((sampling: imaging, waveband summary UV $(\sim 0.01 \mu \mathrm{m}-\sim 0.40 \mu \mathrm{m})$, VIS $(\sim 0.40 \mu \mathrm{m} \quad-\quad 0.75 \mu \mathrm{m}))$ measure ocean chlorophyll concentration and color dissolved organic matter (CDOM).

Next Gen APS instrument: (sampling: imaging, waveband summary VIS $(\sim 0.40 \mu \mathrm{m} \sim \sim 0.75 \mu \mathrm{m}$, NIR $(\sim 0.75 \mu \mathrm{m}-\sim 1.3 \mu \mathrm{m})$, SWIR $(\sim 1.3 \mu \mathrm{m}-\sim 3.0 \mu \mathrm{m}))$ measure Aerosol optical depth (column/profile) and Aerosol Absorption optical depth (column/profile).

Cloud Radar instrument: (sampling: imaging, waveband: Dual frequency: 35 and $94 \mathrm{GHz}, M W(\sim 1.0 \mathrm{~cm}-\sim 100 \mathrm{~cm})$. vertical Resolution $250 \mathrm{~m}$ cross-track: $1.4 \mathrm{~km}$, along-track $2.5 \mathrm{~km}$, instantaneous footprint $<1 \mathrm{~km}$ ), measure Atmospheric Temperature Fields, Cloud Particle properties and profile, Cloud Type, Amount and cloud top temperature, liquid water and precipitation rate and Radiation budget.

LIDAR instrument: (sampling: sounding, waveband: 355, 532, $1064 \mathrm{~nm}$. vertical sampling 30-60 m, -2 to $40 \mathrm{~km}$, along-track $333 \mathrm{~m})$ measure cloud type, Aerosols, amount and cloud top temperature

ACE is a multi-level research satellite; its purpose is to study aerosol and cloud types and their properties as well as measuring ocean productivity in the surface ocean layers (https://eospso.nasa.gov/missions/aerosol-cloud-ecosystems). ACE seeks to differentiate between types of aerosols and measure the cloud hydrometric profiles. Also, this satellite will able to distinguish the components of the ocean ecosystem and determine the amount of carbon uptake of the ocean. So, ACE can respond to questions about aerosols and clouds and ocean ecosystems using cutting edge technology and advanced remote sensing. Following satellite's goals, the ability to observe and anticipate changes in the hydrological cycle of the earth and energy balance in response to climate threats will increase (https://acemission.gsfc.nasa.gov/).

\section{CONCLUSION}

Measuring the vertical distribution of aerosols, clouds, gases, as well as their effects on the climate system can be obtained with the help of the LIDAR systems. The space borne LIDARs were used with high temporal resolution and at the global scales to evaluate these parameters used in weather forecasting and estimation of ice and polar ice changes and oceans. Following some of the satellite constraints and challenges, other satellites were designed and arranged in orbit, with the main purpose of continuing previous missions, as well as filling the gaps. For example, one of the challenges of the ICESat satellite was the problem of measuring the height change for the outlet glaciers, because ICESat carried a single-beam laser altimeter, but, the beam pair configuration of ICESat- 2 allows for the determination of local cross-track slope. This is important for measuring the elevation change for outlet glaciers (Markus et al., 2017). Another challenge is the uncertainty about the impact of aerosols 
on the climate system that limits our understanding of climate change. The problem was solved by the reduced uncertainty in CALIPSO satellite (Winker et al., 2003). Diurnal gap of CALIPSO was covered by real time CATS-ISS observation. It was considered as a bridge between the CALIPSO satellites and EarthCARE satellite, helping to extend the CALIPSO data records. The CATS-ISS satellite was scheduled for at least 6 months and maximum of 3 years, eventually, after 33 months mission of the satellite was finished (Platnick, 2017). Generally, active satellites including RADAR and LIDAR have shorter lifetime in comparison with passive and optic remote sensing. Concerning the applicability, the CALIPSO is known as one of the important satellites which has a long historical data form 2006 until know which makes them more applicable for time series analysis. The most researches have been done using LIDAR observations from CALIPSO (https://wwwcalipso.larc.nasa.gov/resources/bibliographies.php)

comparison with other space borne LIDAR satellites.

\section{REFERENCES}

Abshire, J.B., Sun, X., Riris, H., Sirota, J.M., McGarry, J.F., Palm, S., Yi, D., Liiva, P., 2005. Geoscience laser altimeter system (GLAS) on the ICESat mission: on-orbit measurement performance. Geophys. Res. Lett. 32.

Dessler, A.E., Palm, S.P., Spinhirne, J.D., 2006. Tropical cloudtop height distributions revealed by the ice, cloud, and land elevation satellite (ICESat)/Geoscience laser altimeter system (GLAS). J. Geophys. Res. Atmos. 111.

Eguchi, N., Yokota, T., 2008. Investigation of clear-sky occurrence rate estimated from CALIOP and MODIS observations. Geophys. Res. Lett. 35.

Glenn, N.F., Neuenschwander, A., Vierling, L.A., Spaete, L., Li, A., Shinneman, D.J., Pilliod, D.S., Arkle, R.S., McIlroy, S.K., 2016. Landsat 8 and ICESat-2: Performance and potential synergies for quantifying dryland ecosystem vegetation cover and biomass. Remote Sens. Environ. $185,233-242$

Hayer, C., Carboni, E., Carn, S., Ventress, L., Grainger, R., 2018 Comparison of satellite observations of the atmospheric emissions from the April 2015 eruption of Calbuco volcano, Chile, in: EGU General Assembly Conference Abstracts. p. 18860

Herzfeld, U.C., McDonald, B.W., Wallin, B.F., Neumann, T.A., Markus, T., Brenner, A., Field, C., 2014. Algorithm for detection of ground and canopy cover in micropulse photon-counting lidar altimeter data in preparation for the ICESat-2 mission. IEEE Trans. Geosci. Remote Sens. 52, 2109-2125.

Hughes, E.J., Yorks, J., Krotkov, N.A., da Silva, A.M., McGill, M., 2016. Using CATS near-real-time lidar observations to monitor and constrain volcanic sulfur dioxide (SO2) forecasts. Geophys. Res. Lett. 43, 11-89.

Leifer, I., Lehr, W.J., Simecek-Beatty, D., Bradley, E., Clark, R., Dennison, P., Hu, Y., Matheson, S., Jones, C.E., Holt, B., 2012. State of the art satellite and airborne marine oil spill remote sensing: Application to the BP Deepwater Horizon oil spill. Remote Sens. Environ. 124, 185-209.

Lu, X., Hu, Y., Trepte, C., Zeng, S., Churnside, J.H., 2014. Ocean subsurface studies with the CALIPSO spaceborne lidar. J. Geophys. Res. Ocean. 119, 4305-4317.

Luo, T., Wang, Z., Zhang, D., Liu, X., Wang, Y., Yuan, R., 2015. Global dust distribution from improved thin dust layer detection using A-train satellite lidar observations. Geophys. Res. Lett. 42, 620-628.

Markus, T., Neumann, T., Martino, A., Abdalati, W., Brunt, K., Csatho, B., Farrell, S., Fricker, H., Gardner, A., Harding,
D., Jasinki, M., Kwok, R., Magruder, L., Lubin, D., Luthcke, S., Morison, J., Nelson, R., Neuenschwander, A., Palm, S., Popescu, S., Shum, CK., Schutz, Bob E., Smith, B., Yang, Y., Zwally, J. (2017). The Ice, Cloud, and land Elevation Satellite-2 (ICESat-2): Science requirements, concept, and implementation. Remote Sensing of Environment, $\quad 190, \quad 260-273$. https://doi.org/10.1016/j.rse.2016.12.029

McCormick, M.P., 2005. Airborne and spaceborne lidar, in: Lidar. Springer, pp. 355-397.

Narine, L.L., Popescu, S., Zhou, T., Srinivasan, S., Harbeck, K., 2019. Mapping forest aboveground biomass with a simulated ICESat-2 vegetation canopy product and Landsat data. Ann. For. Res.

Nelson, R., Ranson, K.J., Sun, G., Kimes, D.S., Kharuk, V., Montesano, P., 2009. Estimating Siberian timber volume using MODIS and ICESat/GLAS. Remote Sens. Environ. 113, 691-701.

Noel, V., Chepfer, H., Chiriaco, M., Yorks, J., 2018. The diurnal cycle of cloud profiles over land and ocean between $51^{\circ} \mathrm{S}$ and $51^{\circ} \mathrm{N}$, seen by the CATS spaceborne lidar from the International Space Station. Atmos. Chem. Phys. 18, 9457-9473.

Oppel, U.G., 2000. Hierarchy of models for lidar multiple scattering and its applications for simulation and analysis of spaceborne lidar returns, in: Seventh International Symposium on Atmospheric and Ocean Optics. International Society for Optics and Photonics, pp. 237251.

Ranson, K.J., Sun, G., Kovacs, K., Kharuk, V.I., 2004. Landcover attributes from ICESat GLAS data in central Siberia, in: IGARSS 2004. 2004 IEEE International Geoscience and Remote Sensing Symposium. IEEE, pp. 753-756.

Thomason, L.W., Pitts, M.C., Winker, D.M., 2007. CALIPSO observations of stratospheric aerosols: a preliminary assessment. Atmos. Chem. Phys. 7, 5283-5290.

Wang, X., Huang, H., Gong, P., Liu, C., Li, C., Li, W., 2014. Forest canopy height extraction in rugged areas with ICESAT/GLAS data. IEEE Trans. Geosci. Remote Sens. $52,4650-4657$.

Winker, D., Vaughan, M., Hunt, B., 2006. The CALIPSO mission and initial results from CALIOP, in: Lidar Remote Sensing for Environmental Monitoring VII. International Society for Optics and Photonics, p. 640902.

Winker, D. M., Pelon, J. R., \& McCormick, M. P., 2003. The CALIPSO mission: spaceborne lidar for observation of aerosols and clouds. Lidar Remote Sensing for Industry and Environment Monitoring III, 4893, 1. https://doi.org/10.1117/12.466539

Platnick, S., 2017. The Earth Observer. November - December. Volume 29, Issue 6. 29(6), 1-56.

Platnick, S., 2013. The Earth Observer. May-June 2013. Volume 25, Issue 3, 25(3). Retrieved from http://claspresearch.engin.umich.edu/missions/cygnss/reference/cyg nss-mission/The-Earth-Observer_May-Jun2013 CYGNSS.pd

Neuenschwander, A. L., \& Magruder, L. A., 2016. The potential impact of vertical sampling uncertainty on ICESat-2/ATLAS terrain and canopy height retrievals for multiple ecosystems. Remote Sensing, 8(12). https://doi.org/10.3390/rs8121039 
Poole, L. R., Winker, D. M., Pelon, J. R., \& McCormick, M. P. (2003). CALIPSO: global aerosol and cloud observations from lidar and passive instruments. Sensors, Systems, and NextGeneration Satellites VI, 4881, 419. https://doi.org/10.1117/12.462519

Schutz, B.E., Zwally, H.J., Shuman, C.A., Hancock, D and DiMarzio, J.P., 2005. Overview of the ICESat mission Geophys. Res. Lett, 32, p.L21S01

Zwally, H.J., Schutz, B., Abdalati, W., Abshire, J., Bentley, C., Brenner, A., Bufton, J., Dezio, J., Hancock, D., Harding, D. and Herring, T., 2002. ICESat's laser measurements of polar ice, atmosphere, ocean, and land. Journal of Geodynamics, 34(3-4), pp.405-445.http://doi.org/10.1016/S0264-3707(02)00042-X

Winker, D. M., W. H. Hunt, and M. J. McGill (2007), Initial performance

assessment of CALIOP, Geophysical Research Letters. Res. Lett., 34, L19803. http://doi.org/:10.1029/2007GL030135

Reitebuch, O., 2012. The Spaceborne wind lidar mission ADMAeolus. In Atmospheric Physics_(pp.815-827). springer, Berlin, Heidelberg. https://doi.org/10.1007/978-3-642-30183-4

Dabas, A., Denneulin, M.L., Flamant, P., Loth, C., Garnier, A., Dolfi-Bouteyre, A., 2008. Correcting winds measured with a Rayleigh Doppler lidar from pressure and temperature effects. Tellus A 60, 206-215. https://doi.org/10.1111/j.1600$\underline{0870.2007 .00284 . x}$

Reitebuch, O., Lemmerz, C., Nagel, E., Paffrath, U., Durand, Y., Endemann, M., Fabre, F. and Chaloupy, M., 2009. The airborne demonstrator for the direct-detection Doppler wind lidar ALADIN on ADM-Aeolus. Part I: Instrument design and comparison to satellite instrument. Journal of Atmospheric and Ocean Technology, 26(12), pp.2501-2515. https://doi.org/10.1175/2009jtechal1309.1

Winker, D. M., Pelon, J., \& Pierre, U., 2003. The CALIPSO Mission. 2003. IEEE International Geoscience and Remote Sensing Symposium, 00@, 7929-7931.

Costantino, L. and Bréon, F.M., 2010. Analysis of aerosol-cloud interaction from multi-sensor satellite observation. Geophysical Research Letters, 37(11). https://doi.org/10.1029/2009GL041828

Illingworth, A. J., Barker, H. W., Beljaars, A., Ceccaldi, M., Chepfer, H., Cole, J., Delanoe, J., Domenech, C., Donovan, D. P., Fukuda, S., Hirakata, M., Hogan, R. J., Huenerbein, A., Kollias, P., Kubota, T., Nakajima, T., Nakajima, T. Y., Nishizawa, T., Ohno, Y., Okamoto, H., Oki, R., Sato, K., Satoh, M., Shephard, M., Wandinger, U., Wehr, T., Van Zadelhoff, G. J., 2015. The EarthCARE satellite: The next step forward in global measurements of clouds, aerosols, precipitation, and radiation. Bulletin of the American Meteorological_society, 96(8), 1311-1332. https://doi.org/10.1175/BAMS-D-12-00227.1

Witschas, B., Vieitez, M.O., van Duijn, E.J., Reitebuch, O., van de Water, W. and Ubachs, W., 2010. Spontaneous RayleighBrillouin scattering of ultraviolet light in nitrogen, dry air, and moist air. Applied optics, 49(22), pp.4217-4227. https://doi.org/10.1364/AO.49.004217
Urban, T.J., Schutz, B.E. and Neuenschwander, A.L., 2008. A Survey of ICESat Coastal Altimetry Applications: Continental Coast, Open Ocean Island, and Inland River. Terrestrial, $\begin{array}{llll}\text { Atmospheric \& Oceanic science, } & 19 .\end{array}$ https://doi.org/10.3319/TAO.2008.19.1-2.1(SA)

Nuth, C. and Kääb, A., 2011. Co-registration and bias corrections of satellite elevation data sets for quantifying glacier thickness change. The Cryosphere, 5(1), pp.271-290.

Winker, D.M., Tackett, J.L., Getzewich, B.J., Liu, Z., Vaughan, M.A. and Rogers, R.R., 2013. The global 3-D distribution of tropospheric aerosols as characterized by CALIOP. Atmospheric Chemistry and Physics, 13(6), pp.3345-3361.

Palm, S. P., Hlavka, D.L., Selmer, P., Pauly, R., 2018. Cloud Aerosol Transport (CATS) Data Management System Data Product Catalog. National Aeronautics and Space Administration Goddard Space Flight Center Greenbelt, Maryland 20771 USA.

Baghdadi, N., Lemarquand, N., Abdallah, H., \& Bailly, J. S. (2011). The relevance of GLAS/ICESat elevation data for the monitoring of river networks. Remote Sensing, 3(4), 708-720. https://doi.org/10.3390/rs3040708

Srivastava, P., Bhambri, R., Kawishwar, P., Dobhal, D. P. (2013). Water level changes of high altitude lakes in Himalaya-Karakoram from ICESat altimetry. Journal of Earth System Science, 122(6), 1543. http://doi.org/10.1007/s12040-013-0364-1

Sun, X., Abshire, J.B., Borsa, A.A., Fricker, H.A., Yi, D., DiMarzio, J.P., Paolo, F.S., Brunt, K.M., Harding, D.J. and Neumann, G.A., 2017. ICESat/GLAS altimetry measurements: received signal dynamic range and saturation correction. IEEE Transactions on Geoscience and Remote Sensing, 55(10), pp.5440-5454. https://doi.org/10.1109/TGRS.2017.2702126

Platnick, S. (2013). The March-April Earth Observer Newsletter. 25(April 2013). (https://eospso.nasa.gov/earthobserver/mar-apr-2013) 